\title{
A review of evidence for immunosuppression due to Porcine Reproductive and Respiratory Syndrome Virus
}

\author{
Trevor W. DREW
}

Virology Department, Veterinary Laboratories Agency (Weybridge), Woodham Lane, New Haw, Addlestone, Surrey, KT15 3NB, UK

\begin{abstract}
Accounts of field disease and experimental studies involving porcine reproductive and respiratory syndrome (PRRS) are reviewed for evidence of immunomodulation or immunosuppression by the causative virus. The conclusion is that immunomodulation through infection of alveolar macrophages is likely to occur, but that it is transient and at a local level, in the lung. There is some evidence for more subtle effects via more disseminated replication or induction of apoptosis with some isolates, but more definitive studies are needed. There is some emerging evidence of interaction between PRRSV and different cells of the immune system, but its significance for the course of disease or pig health are unclear. Likewise, the current experimental evidence for any interaction of PRRSV with other pathogens is ambiguous and therefore no firm conclusions can yet be drawn. Strains of PRRSV do vary in pathogenicity, which may be related to their degree of ability to cause overt respiratory disease in the absence of other agents. Experimentally, varying degrees of interstitial pneumonia are a common histological finding. There is, as yet, no firm evidence of general immunosuppression - in fact, some contrary evidence exists in the form of observations of a transient enhancement of humoral response, possibly through polyclonal B cell activation. The basis of pathogenicity of PRRSV and of any interaction with other agents is still unknown and is likely to remain unclear. Virus interaction with the pig's immune system must be addressed before any assessment of virulence of any known or emergent strains of PRRSV can be made.
\end{abstract}

swine disease / PRRSV / coronaviridae / nidovirales / arterivirus / viral immunomodulation / pig

Résumé - Immunosuppression due au virus du syndrome dysgénésique et respiratoire porcin : le point sur les résultats. Une revue bibliographique de rapports de terrain et expérimentaux impliquant le syndrome dysgénésique et respiratoire du porc (PRRS) a permis de faire le point sur les résultats montrant une immunomodulation ou une immunosuppression dues au virus. La conclusion est qu'il est possible que l'infection des macrophages alvéolaires provoque une immunomodulation, mais celle-ci reste transitoire et localisée dans les poumons. Certains résultats suggèrent des effets plus subtils avec certaines souches, faisant intervenir une réplication plus disséminée ou

Tel.: (44) (0) 1932357 637; fax: (44) (0) 1932357 239; e-mail: tdrew.vla@gtnet.gov.uk 
induisant un phénomène d'apoptose, mais des études plus exhaustives sont nécessaires. De récents travaux montrent une interaction entre PRRSV et différentes cellules du système immunitaire, mais son impact sur le déroulement de la maladie ou la santé des porcs demeure incertain. De même, les résultats expérimentaux montrant une interaction entre le PRRSV et d'autres pathogènes sont ambigus et ne permettent pas de tirer de conclusions définitives. Les variations de pathogénicité entre souches virales pourraient dépendre de leur capacité à provoquer des symptômes détectables en l'absence d'autres agents infectieux. Sur le plan expérimental, les observations histologiques montrent souvent des degrés variables de pneumonie interstitielle. Il n'existe donc jusqu'à présent pas de preuve définitive d'une immunosuppression générale - et en fait, certains résultats suggèrent au contraire une augmentation de l'efficacité de la réponse liée aux anticorps, passant par l'activation des cellules polyclonales B. Les facteurs de base de la pathogénicité du PRRSV et des interactions avec d'autres pathogènes sont encore inconnus, et à cause de leur complexité resteront sans doute incertains. Il faudra d'abord élucider les interactions entre le virus et le système immunitaire du porc, avant d'envisager de prédire la virulence des souches connues ou émergentes de PRRSV.

maladie du porc / virus du syndrome dysgénésique et respiratoire porcin / coronaviridae / nidovirales / arterivirus / immunomodulation virale / porc

Table of contents

1. Introduction.

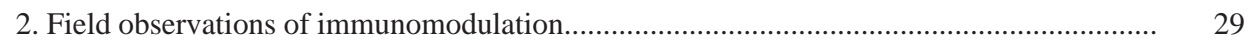

3. Experimental investigations of an immunomodulation theory ........................................ 30

4. Known effects of PRRSV on cells of the immune system ................................................ 31

4.1 Effects on macrophages ....................................................................................... 31

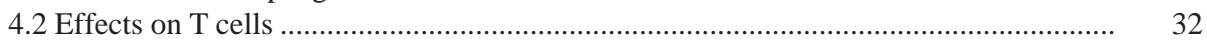

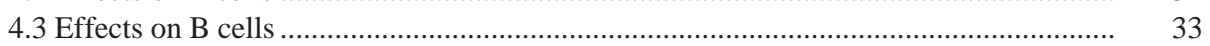

4.4 Effects on other cells.............................................................................. 33

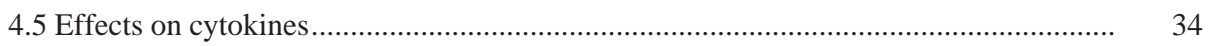

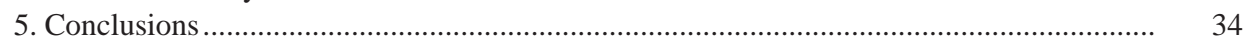

\section{INTRODUCTION}

In the relatively short time since its recognition, much has been described of the aetiology of the PRRS field disease. In particular, investigations of the respiratory form of the disease in field cases, in attempts to identify the causative agent, resulted in the isolation of a number of bacterial and viral agents, including the arterivirus now known to be the primary causative virus of PRRS (PRRSV). This has led to the postulation of interaction between PRRSV and these other agents, in which immunomodulation or immunosuppression by PRRSV has often been suggested, resulting in general acceptance of PRRSV as an immunosuppressive virus.

Much of the research into this disease has focussed on the molecular biology of the causative virus, which has revealed two genotypes, but relatively little definitive work has accrued of the action of PRRSV on the immune system and the consequences thereof, which could help to explain field observations. An explanation of such synergy would be that PRRSV affects the ability of the pig to mount an effective immune response to other pathogens, either through the action of the virus itself, or as a consequence of the host response to the infection affecting the ability of the host to defend itself against other pathogens.

Viruses are known to act as immune modulators in four principal ways:

(a) by interfering with antigen presentation;

(b) by the induction of apoptosis, resulting in the death of cells involved in an immunological response; 
(c) by acting as cytokines or cytokine inhibitors, affecting their production or action;

(d) by inhibiting the complement.

This review will summarise the present knowledge concerning immunomodulation by PRRSV and attempt to evaluate the current evidence for such.

\section{FIELD OBSERVATIONS OF IMMUNOMODULATION}

Early observations of the epidemiology of the syndrome of PRRS suggested an infectious agent, yet it was some time before the causative virus, PRRSV, was discovered [69]. Many pathogens, both viral and bacterial, were initially implicated, by virtue of their isolation from many clinical cases, yet no pathogen was able to reproduce the disease experimentally, neither alone nor in combination $[2,9,12,14,16,22,34,38$, $46,54,62]$. The lack of consistent isolation of any single agent from cases of the disease however, suggested that, rather than being the primary agents, their presence was opportunistic, causing secondary infections leading to multifactorial disease.

The implication of these early observations led to the suspicion that PRRSV may cause immuno-suppression or immunodebilitation. This hypothesis was re-enforced by the demonstrable tropism of the virus for pig alveolar macrophages (PAMs) and certain other cells of the monocyte lineage [50, 68]. PAMs are responsible for the phagocytosis of bacteria in the lungs and are also involved, though not exclusively, in the processing and presentation of viral antigens, which is crucial for mounting an immune response. The present view remains that these other pathogens often contribute to the clinical and histological picture seen in the respiratory form of field cases of PRRS [49, 72, 73].

Field data has been analysed by several groups. Groschup et al. [30] measured anti- body levels to the European strain of PRRSV (EuPRRSV), swine influenza virus (SIV), porcine respiratory coronavirus (PRCV) and to paramyxovirus (PPMV) in pig herds with respiratory disorders. They found significant associations between PRRSV and PRCV, and also with SIV subtype $\mathrm{H}_{1} \mathrm{~N}_{1}$ and postulated that an increased severity of disease may be caused by the promotion of these secondary agents by PRRSV, through synergistic reactions, or by external factors promoting both agents. The cytopathic effect of PRRSV in PAMs, resulting in a reduction in the population of these cells in the lungs of affected pigs, was postulated to be the cause of this phenomenon. An implication of an association between PRRSV and PRCV in Japan was also made by Kamogawa et al. [36]. Kay et al. [37] described an episode of chronic respiratory disease, in a herd in the UK, in which PRRSV and SIV co-infection was detected. Bacterial agents are also implicated as potential synergists in field studies of the respiratory form of PRRS [28, 49]. A retrospective analysis by Zeman [72] identified concurrent pulmonary bacterial infections in $58 \%$ of 221 PRRS cases, most commonly being Pasteurella multocida, Streptococcus suis, Haemophilus parasuis and Salmonella spp., with SIV only rarely being implicated. Done et al. [25] reported minimal gross lesions in pigs in the UK naturally infected with PRRSV alone, with the only consistent finding being an interstitial pneumonia. These lesions were complicated, however, when secondary bacterial agents were present, resulting in pneumonia, as well as arthritis and enteritis.

Circumstantial evidence for an interaction between PRRSV and other disease agents is borne out by the observation that the elimination of PRRSV on farms, by nursery depopulation, resulted in improved growth with decreased isolation and association of disease with secondary pathogens $[23,24]$. It could be argued, however, that such husbandry control methods, designed to eliminate PRRSV, would also reduce the 
transmission of these other pathogens. Polson [53] identified differences in management and the presence of other viral and/or bacterial agents as significant in affecting the course and impact of the syndrome of PRRS within herds.

\section{EXPERIMENTAL INVESTIGATIONS OF AN IMMUNOMODULATION THEORY}

The first paper to describe the pathological effects of experimental PRRSV infection [51] implicates cells of the immune system as the target for PRRSV in identifying alveolar macrophages and bronchiolar epithelial cells as containing viral antigens. These workers also observed the presence of viral antigens in splenic macrophages.

Since that time, a large number of workers have attempted clinical experiments to investigate the effects of dual infections involving PRRSV and other pathogens, but their findings continue to be rather ambiguous. As a result, these studies have largely failed to implicate PRRSV in exacerbation of disease or to shed any light on the effects of PRRSV on the immune system. This ambiguity may be due to a number of factors, including the particular strain of PRRSV and/or the secondary pathogen used, the timing of such challenge and the status and immunological history of the pigs involved. Cooper et al. [21] were unable to potentiate infections by challenge of 4-5 week-old specific pathogen-free (SPF) pigs with $H$. parasuis, $S$. suis, $S$. cholerasuis or P. multocida seven days after infection with an American PRRSV strain (AmPRRSV). But Galina et al. [28], using the virulent strain of $S$. suis serotype 2 (DH5) in SPF piglets, observed that only those which had previously been inoculated with EuPRRSV developed clinical signs, a suppurative meningitis and large numbers of the bacteria in tissues, including the brain and meninges. The authors later postulated that the observed interaction of PRRSV with $S$. suis was not through the destruction of macrophages, but rather that PRRSV inflames and destroys the nasal mucosa, resulting in phagocyte infiltration and uptake of $S$. suis to the brain [49].

Van Reeth et al. [66] demonstrated that EuPRRSV interacted with both SIV and, to a lesser extent, with PRCV, to produce more severe disease over a 15 day period of observation. However, a study by Brun et al. [11] failed to detect any interaction between PRRSV and SIV that resulted in an increase in clinical severity, though seroconversion to SIV was higher in the dual-infected group. Pol et al. [52] likewise obtained ambiguous results in experiments involving co-infections of PRRSV with swine influenza and Actinobacillus pleuropneumoniae in SPF pigs.

A study by van Alstine et al. [65] showed that challenge of piglets with Mycoplasma hyopneumoniae seven days after AmPRRSV infection did not result in exacerbation of the disease. A comprehensive study by Albina et al. [1] examined the effects of a prior infection with EuPRRSV on the course of infection with $M$. hyopneumoniae and also with Aujeszky's disease (AD). They found no evidence of increased prevalence of clinical signs or severity of the disease among dual-infected groups, compared to controls. These workers also made an assessment of the effect of PRRSV infection on vaccination against $\mathrm{AD}$, using recombinant proteins $\mathrm{gB}$ and $\mathrm{gC}$ of that virus. They found no significant difference in antibody responses to the AD vaccine among pigs previously infected with PRRSV, compared to controls, but did observe that, 1-2 weeks after challenge with the AD virus, pigs in the PRRSV-infected group produced significantly higher antibody titres to AD compared to animals not previously infected. Furthermore, pigs infected with PRRSV prior to vaccination with AD lost less weight after the AD challenge. The authors conclude that a prior infection with PRRSV transiently enhances 
the immune response to other antigens. This conclusion supports the findings of Molitor et al. [43], who found an increased response to killed $\mathrm{AD}$ virus and to Brucella abortus pili antigen, 1 day and 16 days after AmPRRSV infection. Prior infection with PRRSV had no significant effect on the course of a transmissible gastroenteritis virus (TGEV) infection in SPF piglets [70].

\section{KNOWN EFFECTS OF PRRSV ON CELLS OF THE IMMUNE SYSTEM}

The predilection of PRRSV for cells of the immune system has led to logical assumptions of consequent immunosuppression [45], but it is debatable as to whether the evidence for such actually exists, or whether this is a general feature of all strains of PRRSV.

\subsection{Effects on macrophages}

PRRSV infection of PAMs in vitro results in the rapid death of the cell, usually within 24 hours $[8,48]$. The exact mechanism of cell death is unknown, but is likely to be through apoptosis. The gp5 protein of the virus, encoded by ORF5, has been shown to induce this phenomenon in cells in vitro [61]. Apoptotic events are not only restricted to infected cells. Recently, Sirinarumitr et al. [59] described the death by apoptosis of bystander cells in a cell line, rather than those infected with either of two different strains of AmPRRSV studied. These workers also examined infected lungs for evidence of apoptosis. This was seen in PAMs, but also in intravascular macrophages, and in mononuclear cells. Apoptotic tangible body macrophages and mononuclear cells were also detected in lymph nodes. A recent in vitro functional analysis of EuPRRSV-infected macrophages has been described by Oleksiewicz et al. [47], who noted an up to $40 \%$ reduction in the total number of phagocytozing cells consequent with infection. They found that, whilst the ability of PRRSV-infected macrophages was diminished, uninfected macrophages were unaffected, indicating a lack of soluble suppressive factors being induced in their study.

Whilst it is generally considered that transmission of PRRSV is primarily through infection of PAMs via the respiratory route, certain isolates of PRRSV from the USA are claimed not to be able to infect these cells in vitro [6], though the reason for this somewhat surprising apparent refractivity is unknown.

Comparisons of the effects of PRRSV on different classes or breeds of pigs have not been performed, but there is some data on bronchial cell populations, and these vary greatly, probably through differences in lavage techniques, breed and age. The general consensus is that healthy SPF and conventionally-reared pigs have 93-96\% macrophages, with lymphocyte populations comprising $3-5 \%$ of the total, $2-4 \%$ neutrophils and minor populations $(\sim 0.1 \%)$ of eosinophils, basophils and blast cells [29]. A study of PAMs revealed five distinct subpopulations, with varying susceptibility to PRRSV infection [15]. The relative numbers of these sub-populations vary with the age of the pig, and are also dependent on the disease status of the pig. Such changes in PAM sub-population levels may have a bearing on determining the overall response of the pig to immuno-stimulation or viral challenge. The percentage of susceptible PAMs at any point in time could also affect the degree of any immuno-modulation suffered by the pig as a result of destruction of these cells by PRRSV. A higher percentage of cells with higher susceptibilities to PRRSV are present in young piglets. As a result, there are higher levels of PRRSV replication in vivo [57]. This may help to explain field observations of these younger animals being more susceptible to the respiratory form of PRRS [27]. Shibata et al. [57] demonstrated viral antigens in the cells 
of bronchial lavage fluid for up to 49 days post-infection, demonstrating that PRRSV persists in such cells long after serum viraemia.

In an attempt to further elucidate the varying susceptibility of macrophage subpopulations within the lung, Thanawongnuwech et al. [63] studied the in vitro effects of low and high pneumovirulent strains of PRRSV on pulmonary intravascular and alveolar macrophages from SPF pigs of different ages. They found that intravascular macrophages from younger pigs were more susceptible to infection, yet they could not distinguish between virulent and low virulent viruses in this system, suggesting that the factors involved in virulence lay outside this phase.

Macrophage populations in infected pigs have been demonstrated to be dysfunctional at 7 days post-infection, being impaired in their ability to synthesise superoxide in response to stimulation [44]. The percentage of these cells in lung lavages can drop from $>95 \%$ to $50 \%$ at 7 days post-infection, with a significant suppression of non-specific bactericidal activity of the remaining PAMs [43]. However, these PAMs in the lungs of pigs 28 days post-infection showed enhanced superoxide synthesis compared to controls. This phenomenon seems to be a feature of viral infections of macrophages in general, rather than being specific to PRRSV [39].

In conclusion, it seems that the effects of PRRSV infection are directly on the infected macrophages and that the loss of phagocytic function is due to the effects of replication within the cell, culminating in cell death. Apoptosis of uninfected cells has also been observed in vitro.

\subsection{Effects on $T$ cells}

An early study of peripheral T-cell populations of growing pigs showed their numbers to drop transiently at 14 days post-infec- tion [74]. In a more detailed experiment, Shimizu et al. [58] examined the changes in lymphocyte sub-populations during the course of natural and experimental AmPRRSV (Japanese source) infection of SPF pigs. They found increases in $\mathrm{CD} 2^{+}$ and $\mathrm{CD}^{+}$cells, with a decrease in $\mathrm{CD} 4^{+}$ cells and the ratio of $\mathrm{CD}^{+} / \mathrm{CD}^{+}$cells. The decline in $\mathrm{CD}^{+}{ }^{+}$cell population (which include T-helper cells, involved in immunological memory) continued for at least 14 days, whilst $\mathrm{CD}^{+}$cells (a marker for cytotoxic T-cells, which recognise virus-infected cells) increased, peaking on days 28-35. An attempt to induce proliferation by in vitro stimulation of cultured cells failed, suggesting that the effects of PRRSV on these cells is not a direct one. This work expanded on the earlier observation of Christianson et al. [18], who obtained similar results, but terminated their observations at 14 days post-infection. Certainly, PRRSV is known to persist in pigs for up to 2-3 months postinfection $[1,19,26]$, so experiments such as those described should be extended to explore the long-term effects of PRRSV, if any, on the immune system. Not all the published data of sub-cell populations are in accord. As Shimizu et al. [58] indicate, their results are in direct conflict with those of Zhou et al. [74], who observed an increase in $\mathrm{CD}^{+}$cells and a decrease in $\mathrm{CD} 8^{+}$cells in young pigs. A proffered explanation for this was the variation in pathogenicity among PRRSV strains. Bautista and Molitor [5] have provided a basic model for T-cell studies, describing the kinetics of the T-cell proliferation response, both after primary and secondary infection. They detected an increased level of proliferation response after secondary exposure and showed that this was due to $\mathrm{CD} 4^{+}$cells which were effectors in this response.

Furthermore, they showed that, in vivo, there was a dose-dependent delayed-type hypersensitivity (DTH) response in infected pigs following intra-dermal challenge with inactivated PRRSV. 
Many theories have been offered proposing a mechanism whereby PRRSV may alter the population of T-cell sub-sets. Parallels with other virus infections give rise to suggestions of $\mathrm{CD}^{+}{ }^{+} \mathrm{T}$-cell death, perhaps with concurrent $\mathrm{CD} 8^{+}$stimulation or that the virus may act at the level of T-cell intrathymic differentiation. Shimizu et al. [58] have proposed that a certain, as yet unidentified physiological stimulus, induced as a consequence of PRRSV infection, may be the cause of $\mathrm{CD}^{+}$cell proliferation.

\subsection{Effects on B cells}

The study of the blastogenic response of peripheral blood lymphocytes from PRRSVinfected SPF piglets, by Vézina et al. [67], detected a transient diminution of the proliferative response of these cells at 3 days post-infection. These workers also detected an in vitro proliferative activity of mononuclear cells in the absence of any mitogen, which persisted over time, suggesting a polyclonal B-cell activation - a phenomenon also reported for another arterivirus, lactate dehydrogenase-elevating virus of mice (LDV) [10].

A feature of PRRSV infections is the persistence of the virus within the infected animal in the presence of a vigorous humoral response, but the exact mechanism of tolerance that leads to this phenomenon is unknown. Such antibody has been shown to enhance uptake of the virus by susceptible cells [71]. Studies of the immune response to individual viral proteins have been reported [40, 42], showing that antibody responses are mounted primarily to the nucleocapsid ( $\mathrm{N}$, encoded by ORF7), and, to a lesser extent, to the matrix protein (M, encoded by ORF6) and to the major envelope protein ( $\mathrm{E}$ or gp5, encoded by ORF5). Within one week of infection, IgM responses are detectable, peaking at 14-21 days and rapidly decreasing, being undetectable by $35-42$ days. IgG titres peak at 21 to 28 days and are detectable for several months. The difference in the response to these PRRSV proteins has been postulated to be consequent to their molar ratio within the virion, rather than their immunogenicity [40]. It is possible that one of the PRRSV proteins may act as a superantigen [64], cross-linking B- and T-cells via MHC II and $\mathrm{T}$-cell receptors to induce the effects described. Albina et al. [3] also detected a stimulating effect on the pig immune system, after studying the immune functions of EuPRRSV-infected pigs super-infected with Aujeszky's disease. Total WBC count and the number of $\operatorname{IgM}^{+}, \mathrm{CD} 2^{+}$and $\mathrm{CD} 8^{+}$ cells were enhanced, with the increase in the latter persisting for three consecutive weeks post-infection. These workers also detected a slightly diminished DTH response to phytohaemagglutinin after one week, but which was restored thereafter.

\subsection{Effects on other cells}

Macrophages are not the only cells shown to be infected by PRRSV. Cell lymphocyte and monocyte populations in sows drop during the course of infection with PRRSV [17]. Cells of the monocyte lineage have been shown to be susceptible to PRRSV infection in vitro [68] and the PRRSV antigen has been demonstrated in lung endothelial cells, macrophages in the heart and also in cells resembling dendritic cells in the tonsils, lymph nodes, thymus and spleen [31]. The consequences of virus infection on the function and longevity of these cells are unknown. Immunohistochemistry was also employed in a time-based study of AmPRRSV infection in gnotobiotic pigs [55]. At 12 hours, PRRSV antigen was especially evident in interstitial, alveolar and intravascular macrophages, but was also seen in monocytes, and also in epithelial cells of the bronchus and arterioles. Tonsillar macrophages and mucosal epithelium also contained viral antigen at this time, though to a lesser extent. At 14 and 21 days post-infection, the viral antigen was detected 
in epithelial and macrophage cells in the heart - confirming the findings of Halbur et al. [31].

The placenta has also been identified as a target organ for PRRSV [60] which is consistent with the observed effects of the virus on pigs in late pregnancy. The effects can be dramatic, resulting in abortions, stillbirths, mummifications, and the birth of weak, undersized piglets, through fetal hypoxia and diminished nutrient supply. The virus also crosses the placenta, resulting in fetal infection, but no studies have been reported of the consequent effects on the immunocompetence of PAMs or other lymphoid cells of piglets infected trans-placentally with PRRSV.

Rossow et al. [56] noted the appearance of strains of AmPRRSV with a marked neurovirulence, and have demonstrated viral replication within macrophages and microglial cells in lesions of the cerebral cortex. It is unclear whether this recent development is associated with the immune status of affected pigs, since the disease has only been seen in herds with a history of PRRSV and which had been vaccinated with an attenuated PRRSV vaccine. Nor is it clear whether the affected animals were infected ante- or post-natally. An analysis of envelope glycoproteins revealed differences between these strains and the strain used in the vaccine, but the course of infection that led to this manifestation remains unknown.

\subsection{Effects on cytokines}

This is perhaps the least studied of the known effects of PRRSV on the pig immune system. Interferons are commonly produced by virus-infected cells and Albina et al. [2] showed that interferon-alpha (IFN $\alpha$ ) inhibited growth of EuPRRSV in vitro, and that low concentrations of IFN $\alpha$ were detectable in the serum of infected pigs, but somewhat surprisingly, not in lung secretions. A series of in vitro experiments revealed that no IFN $\alpha$ was produced following infection of cells with PRRS. Moreover, super-infection of PAMs with transmissible gastroenteritis virus (normally a good inducer of IFN $\alpha$ ), failed to induce IFN $\alpha$ production. These findings led these workers to postulate that IFN $\alpha$ production in PAMs and peripheral blood monocytes may be down-regulated following PRRSV-infection.

A study of the effects of tumour necrosis factor (TNF) and INFy on the replication of LDV by Cafruny et al. [13], showed that when these cytokines were given to mice, they reduced the subsequent in vitro permissiveness of their macrophages to LDV; however, the same effect was not seen if the cells were treated with the cytokines directly, in vitro. They concluded that the effects were therefore secondary or accessory in vivo and that cytokines may be involved in the regulation of LDV levels in mice and the virus-host relationship.

\section{CONCLUSIONS}

The current view is in line with previous recent reviews of this subject [7, 25, 41] which conclude that, whilst there is some field evidence of immuno-compromisation of pigs following PRRSV infection, the experimental evidence is somewhat ambiguous. It is likely that any effects are due to a transient deterioration of local lung cellular defences, which is difficult to reproduce experimentally. Any effects due to PRRSV are therefore likely to be short-lived, with immune function returning to normal within three weeks. The polyclonal B-cell response that has been observed with infection with PRRSV and other arteriviruses, has been shown to enhance the humoral response to subsequent infection with other agents and to vaccinal antigens. Such activation could be due to one or more viral proteins acting as superantigens, but further elucidation of any immunomodulation of immunity by PRRSV, by this or other mechanisms, must await the results of analyses of the effects of viral proteins on the cellular and humoral 
response of the pig. Such an approach would also elucidate any differences among global types or strains of PRRSV.

Much of the field and experimental work described has been limited to observations or measurements of the effects of individual strains of PRRSV on specific classes of pigs. The variation in pathogenesis of different isolates of PRRSV is well documented [20, $32,35]$. Pathological studies have led workers to postulate that it is related to their ability to replicate in vivo [33] though it is possible that such pathogenesis may also be related in part to the ability of certain strains to evade or modify the immune system of the host. The highly pathogenic PRRSV that was reported in the mid-western states of the USA [4] and the emergence of highly neuropathic strains [56] makes generalisations imprudent, as the basis of such heightened pathogenicity is, as yet, unknown.

The existence of two distinct genotypes of PRRSV has been known for many years, but many authors do not clearly distinguish the genotype associated with a particular study. I propose that, in line with the nomenclature of many other viruses, PRRSV of the European type, with 128 amino acids in the nucleocapsid, be called PRRSV type 1, since it was the first to be isolated and the American type, having 123 amino acids, be termed PRRSV type 2. fore:

The conclusions of this review are there-

- Immunomodulation is likely to be transiently present, at a local level, in the lung. General immunosuppression is possible, particularly with some strains, but not proven. The degree of such immunomodulation and its significance for pig health are, at this time, still unclear. But concurrent bacterial infection is a common feature of the respiratory disease in which PRRSV is involved. The experimental evidence of interaction of PRRSV with other pathogens is still ambiguous and no firm conclusions can yet be drawn. Where specific implica- tions for synergism occur, they should be repeated under rigorously controlled conditions to ensure the validity of any data. In particular, the possibility of contamination of experimental PRRSV inoculae should be addressed.

- Strains of PRRSV may vary in their ability to cause overt respiratory disease in the absence of other agents. Experimentally, however, varying degrees of interstitial pneumonia are a common histological finding.

Despite claims, general immunosuppression has not been proven - in fact, there exists certain experimental evidence to the contrary.

Future work should concentrate on the interaction of PRRSV on its host, and in particular, on the interaction with the various facets of the pig immune system and the long-term effects of the virus on surviving piglets infected in utero. Other factors involved in virulence of PRRSV may be virus-encoded, so the mechanism of viral replication and the effects of soluble factors should be further explored.

Any virus used in experimental work should be characterised in terms of its genotype (PRRSV type 1 or type 2), so that, should any differences in virus-host interaction between genotypes or strains become apparent, a retrospective examination of the published work will provide a more valuable analysis.

\section{REFERENCES}

[1] Albina E., Madec F., Cariolet R., Torrison J., Immune response and persistence of the reproductive and respiratory syndrome virus in infected pigs and farm units., Vet. Rec. 134 (1994) 567573 .

[2] Albina E., Carrat C., Charley B., Interferon-alpha response to swine arterivirus (Poav), the porcine reproductive and respiratory syndrome virus, J. Interferon Cytokine Res. 18 (1998) 485-490.

[3] Albina E., Piriou L., Hutet E., Cariolet R., L'Hospitalier R., Immune responses in pigs infected with porcine reproductive and 
respiratory syndrome virus (PRRSV), Vet. Immunol. Immunopathol. 61 (1998) 49-66.

[4] Anon, Mystery US virus could be new PRRS strain, Animal Pharm 365 (1997) 9.

[5] Bautista E.M., Molitor T.W., Cell-mediatedimmunity to porcine reproductive and respiratory syndrome virus in swine, Viral Immunol. 10 (1997) 83-94.

[6] Bautista E.M., Goyal S.M., Yoon I.J., Joo H.S., Collins J.E., Comparison of porcine alveolar macrophages and CL 2621 for the detection of porcine reproductive and respiratory syndrome (PRRS) virus and anti PRRS antibody, J. Vet. Diagn. Invest. 5 (1993) 163-165.

[7] Beilage E.G., The role of infection with the PRRS virus for respiratory disease in swine - a literature review, Deutsche Tierarztliche Wochenschrift 102 (1995) 457-469.

[8] Bloemraad M., de Kluijver E.P., Petersen A., Burkhardt G., Wensvoort G., Porcine reproductive and respiratory syndrome: Temperature and $\mathrm{pH}$ stability of Lelystad virus and its survival in tissue specimens from viraemic pigs., Vet. Microbiol. 42 (1994) 361-371

[9] Bolin C.A., Cassells J.A., Isolation of Leptospira interrogans serovar bratislava from stillborn and weak pigs in Iowa, J. Am. Vet. Med. Assoc. 196 (1990) 1601-1604.

[10] Bradley D.S., Broen J.J., Cafruny W.A., Infection of SCID mice with lactate dehydrogenaseelevating virus stimulates B cell activation, Viral Immunol. 4 (1991) 59-70.

[11] Brun A., Charreyre C., Vaganay A., Reynaud G., Porcine reproductive respiratory syndrome; role of other infectious agents in the respiratory disease of swine, Proceedings of the 13th International Pig Veterinary Congress, Bangkok, Thailand, 26th-30th June (1994) 52

[12] Busse F.-W., Alt M., Janthur I., Neumann W., Shloss P., Epidemiological studies in connection with epidemic late abortion in sows in the WeserEms region of North West Germany., Tieraerztl. Umsch. 46 (1991) 708-717.

[13] Cafruny W.A., Bradley S.E., Broen J.J., Wong G.H.W., Cytokine regulation of lactate dehydrogenase-elevating virus: Inhibition of viral replication by interferon-gamma, Antiviral Res. 23 (1994) 191-201.

[14] Carlson J., Encephalomyocarditis virus (EMCV) as a cause of reproductive and respiratory disease in swine, American Association of Swine Practitioners Newsletter 4 (1992) 23.

[15] Choi C., Gustafson K., Chinsakchai S., Hill H., Molitor T., Heterogeneity of porcine alveolar macrophage subpopulations: Immune functions and susceptibility to PEARS virus., Proceedings of the 13th International Pig Veterinary Congress, Bangkok, Thailand, 26th-30th June (1994) 97.

[16] Christianson W.T., Kim H.S., Joo H.S., Barnes D.M., Reproductive and neonatal losses associated with possible encephalomyocarditis infection in pigs, Vet. Rec. 126 (1990) 54-57.

[17] Christianson W.T., Collins J.E., Benfield D.A., Harris L., Molitor T.W., Pathogenesis of swine infertility and reproductive syndrome virus infection in pregnant sows, Proceedings of the 12th Congress of the International Pig Veterinary Society, The Hague, Netherlands, 17-20 August (1992) 110.

[18] Christianson W.T., Choi C.S., Collins J.E., Molitor T.W., Morrison R.B., Joo H.S., Pathogenesis of porcine reproductive and respiratory syndrome virus infection in mid-gestation sows and fetuses, Can. J. Vet. Res. 57 (1993) 262-268.

[19] Christopher-Hennings J., Nelson E.A., Hines R.J., Nelson J.K., Swenson S.L., Zimmerman J.J., Chase C.C.L., Yaeger M.J., Benfield D.A., Persistence of porcine reproductive and respiratory syndrome virus in serum and semen of adult boars, J. Vet. Diagn. Invest. 7 (1995) 456-464.

[20] Collins J.E., Rossow K.D., Pathogenesis of PRRS, Proceedings of the Allen D. Leman Swine Conference, University of Minnesota, USA (1993) 47-48.

[21] Cooper V.L., Doster A.R., Hesse R.A., Harris N.B., Porcine reproductive and respiratory syndrome: NEB-1 PRRSV infection did not potentiate bacterial pathogens, J. Vet. Diagn. Invest. 7 (1995) 313-320.

[22] Dea S., Bilodeau R., Martineau G.P., Isolation of encephalomyocarditis virus among stillborn and post-weaning pigs in Quebec., Archives of Virology 117 (1991) 121-128.

[23] Dee S.A., Joo. H.S., Elimination of porcine epidemic abortion and respiratory syndrome (PEARS) virus spread in endemically infected swine herds by nursery depopulation., Proceedings of the 13th International Pig Veterinary Congress, Bangkok, Thailand, 26th-30th June (1994) 65.

[24] Dee S.A., Morrison B., Joo H.S., Eradicating porcine reproductive and respiratory syndrome (PRRS) virus using two-site production and nursery depopulation, Swine Health and Production 1 (1993) 20-23.

[25] Done S.H., Paton D.J., Porcine reproductive and respiratory syndrome: Clinical disease, pathology and immunosuppression, Vet. Rec. 136 (1995) 32-35.

[26] Done S.H., Paton D.J., Drew T.W., Cooley W. Spencer Y., The pathology of experimental infections with UK isolates of porcine reproductive and respiratory syndrome virus (PRRSV) in specific pathogen-free pigs, Pig Veterinary Journal 36 (1996) 31-42.

[27] Done S.H., Paton D.J., White M.E.C., Porcine reproductive and respiratory syndrome (PRRS) - A review, with emphasis on pathological, virological and diagnostic aspects, Br. Vet. J. 152 (1996) 153-174. 
28] Galina L., Pijoan C., Sitjar M., Christianson W.T., Rossow K., Collins J.E., Interaction between Streptococcus suis serotype-2 and porcine reproductive and respiratory syndrome virus in specific pathogen-free piglets, Vet. Rec. 134 (1994) 60-64.

[29] Ganter M, Hensel A., Cellular variables in bronchiolar lavage fluids (BALF) in selected healthy pigs., Res. Vet. Sci. 63 (1997) 215-217.

[30] Groschup M.H., Brun A., Haas B., Serological studies on the potential synergism of porcine reproductive and respiratory syndrome virus and influenza-, corona- and paramyxoviruses in the induction of respiratory symptoms in swine, Zentralbl. fur Veterinaermed. Reihe B 40 (1993) 681689.

[31] Halbur P.G., Miller L.D., Paul P.S., Meng X.J., Huffman E.L., Andrews J.J., Immunohistochemical identification of porcine reproductive and respiratory syndrome virus (PRRSV) antigen in the heart and lymphoid system of threeweek-old colostrum-deprived pigs, Vet. Pathol. 32 (1995) 200-204.

[32] Halbur P.G., Paul P.S., Frey M.L., Landgraf J., Eernisse K., Meng X.J., Lum M.A., Andrews J.J., Rathje J.A., Comparison of the pathogenicity of two US porcine reproductive and respiratory syndrome virus isolates with that of the Lelystad virus, Vet. Pathol. 32 (1995) 648-660.

[33] Haynes J.S., Halbur P.G., Sirinarumitr T., Paul P.S., Meng X.J., Huffman E.L., Temporal and morphologic characterization of the distribution of porcine reproductive and respiratory syndrome virus (PRRSV) by in situ hybridization in pigs infected with isolates of PRRSV that differ in virulence, Vet. Pathol. 34 (1997) 39-43.

[34] Hoefling, D.C., Mystery swine disease, Proceeding of the Ninety-fourth Annual Meeting of the United States Animal Health Association, Denver, Colorado, USA, October 6-12, 1990, pp. 501-504.

[35] Joo H.S., Yoon I.J., Virologic, serologic and pathogenic differences of porcine epidemic abortion and respiratory syndrome (PEARS) virus isolates, Proceedings of the 13th International Pig Veterinary Congress, Bangkok, Thailand, 26th-30th June (1994) 57.

[36] Kamogawa O., Tomita Y., Kaneko M., Yamada S., Kubo M., Shimizu M., Isolation of porcine respiratory coronavirus from pigs affected with porcine reproductive and respiratory syndrome, $\mathrm{J}$. Vet. Med. Sci. 58 (1996) 385-388.

[37] Kay R.M., Done S.H., Paton D.J., Effect of sequential porcine reproductive and respiratory syndrome and swine influenza on the growth and performance of finishing pigs, Vet. Rec. 135 (1994) 199-204.

[38] Keffaber K., Stevenson G., Van Alstine W., Kanitz C., Harris L., Gorcyca D., Schlesinnger K., Schultz R., Chadek D., Morrison R., SIRS virus infection in nursery/grower pigs, American
Association of Swine Practitioners Newsletter 4 (1992) 38-40.

[39] Kreil T.R., Eibl M.M., Viral infection of macrophages profoundly alters requirements for induction of nitric oxide synthesis, Virology 212 (1995) 174-178

[40] Loemba H.D., Mounir S., Mardassi H., Archambault D., Dea S., Kinetics of humoral immune response to the major structural proteins of the porcine reproductive and respiratory syndrome virus, Arch. Virol. 141 (1996) 751-761.

[41] Meredith M.J., Porcine reproductive and respiratory syndrome (PRRS), Pig Disease Information Centre, Department of Clinical Veterinary Medicine, University of Cambridge, UK, Boehringer Ingelheim Vetmedica GmbH (1995) ISBN 0-9520409-7-2, p. 81.

[42] Meulenberg J.J.M., Petersen-den Besten A., De Kluyver E.P., Moormann R.J.M., Schaaper W.M.M., Wensvoort G., Characterization of proteins encoded by ORFs 2 to 7 of Lelystad virus, Virology 206 (1995) 155-163.

[43] Molitor T, Leitner G, Choi C, Risdahl J, Rossow $\mathrm{K}$, Collins J, Modulation of host immune responses by SIRS virus, American Association of Swine Practitioners Newsletter 4 (4) (1992) 27-28.

[44] Molitor T.W., Leitner G., Choi C.S., Risdahl J., Rossow K.D., Collins J.E., Does SIRS virus cause immunosuppression?, Proceedings of International Symposium on SIRS/ PRRS/ PEARS (1992) 20.

[45] Molitor T.W., Bautista E.M., Choi C.S., Immunity to PRRSV: Double-edged sword, Vet. Microbiol. 55 (1997) 265-276.

[46] Noack K., Liebermann H., Encephalomyocarditis virus infection in pigs a review., Tieraerztl. Umsch. 47 (1992) 16-18.

[47] Oleksiewicz M.B., Nielsen J., Effect of porcine reproductive and respiratory syndrome virus (PRRSV) on alveolar lung macrophage survival and function, Vet. Microbiol. 66 (1999) 15-27.

[48] Paton D.J., Brown I.H., Scott A.C., Done S.H., Edwards S., Isolation of a Lelystad virus-like agent from British pigs and scanning electron microscopy of infected macrophages, Vet. Microbiol. 33 (1992) 195-201

[49] Pijoan C., Solano G., Segales J., PRRS virus and secondary disease, Proceedings of the 1994 Allen D. Leman Swine Conference, Minnesota, USA (1994) 225-226.

[50] Pol J., Wagenaar F., Morphogenesis of Lelystad virus in porcine alveolar macrophages, American Association of Swine Practitioners Newsletter 4 (1992) 29.

[51] Pol J.M.A., van Dijk J.E., Wensvoort G., Terpstra C., Pathological, ultrastructural, and immunohistochemical changes caused by Lelystad virus in experimentally induced infections of mystery swine disease (synonym: porcine epidemic 
abortion and respiratory syndrome (PEARS)), Vet. Q. 13 (1991) 137-143.

[52] Pol J., van Leengoed L., Stockhofe-Zurwieden N., Wensvoort G., Dual infections of PRRS/influenza or PRRS/APP in the respiratory tract., Abstracts of the Second International Symposium on Porcine Reproductive and Respiratory Syndrome (PRRS), Copenhagen, Denmark, August 9th-10th, (1995) 22.

[53] Polson D.D., Assessing the cost of endemic reproductive and suckling piglet disease in the swine breeding herd, Abstracts of the Second International Symposium on Porcine Reproductive and Respiratory Syndrome (PRRS), Copenhagen, Denmark, August 9th-10th (1995) 47-48.

[54] Reotutar R., Swine reproductive failure syndrome mystifies scientists, J. Am. Vet. Med. Assoc. 195 (1989) 425-428.

[55] Rossow K.D., Benfield D.A., Goyal S.M., Nelson E.A., Christopher-Hennings J., Collins J.E., Chronological immunohistochemical detection and localization of porcine reproductive and respiratory syndrome virus in gnotobiotic pigs, Vet. Pathol. 33 (1996) 551-556.

[56] Rossow K.D., Shivers J.L., Yeske P.E., Polson D.D., Rowland R.R.R., Lawson S.R., Murtaugh M.P., Nelson E.A., Collins J.E., Porcine reproductive and respiratory syndrome virus infection in neonatal pigs characterised by marked neurovirulence, Vet. Rec. 144 (1999) 444-448.

[57] Shibata I., Mori M., Uruno K., Samegai Y., Okada M., In vivo replication of porcine reproductive and respiratory syndrome virus in swine alveolar macrophages and change in the cell population in bronchoalveolar lavage fluid after infection, J. Vet. Med. Sci. 59 (1997) 539-543.

[58] Shimizu M., Yamada S., Kawashima K., Ohashi S., Shimizu S., Ogawa T., Changes of lymphocyte subpopulations in pigs infected with porcine reproductive and respiratory syndrome (PRRS) virus, Vet. Immunol. Immunopathol. 50 (1996) 19-27.

[59] Sirinarumitr T., Zhang Y.J., Kluge J.P., Halbur P.G., Paul P.S., A pneumo-virulent United States isolate of porcine reproductive and respiratory syndrome virus induces apoptosis in bystander cells both in vitro and in vivo. J. Gen. Virol. 79 (1998) 2989-2995

[60] Stockhofe-Zurwieden N., Camarro J.A.N., Grosse-Beilage E., Chavez J., Pohlenz J., Uterine and placental alterations in pregnant sows associated with the porcine epidemic abortion and respiratory syndrome (PEARS), J. Vet. Med. Ser. B - Zentralbl. Fur Veterinaermed. Reihe B Infectious Diseases Immunobiology Food Hygiene Public Health 40 (1993) 261-271.

[61] Suárez P., Diaz-Guerra M., Prieto C., Esteban M., Castro J.M., Nieto A., Ortin J., Open reading frame 5 of porcine reproductive and respiratory syndrome virus as a cause of virus-induced apoptosis, J. Virol. 70 (1996) 2876-2882.
[62] Terpstra C., Wensvoort G., Pol J.M.A., Experimental reproduction of porcine epidemic abortion and respiratory syndrome (mystery swine disease) by infection with Lelystad virus: Koch's postulates fulfilled, Vet. Q. 13 (1991) 131-136.

[63] Thanawongnuwech R., Halbur P.G., Andrews J.J., Immunohistochemical detection of porcine reproductive and respiratory syndrome virus antigen in neurovascular lesions, J. Vet. Diagn. Invest. 9 (1997) 334-337.

[64] Tumang J.R., Cherniak E.P., Gietle D.M., Cole B., Russo C., Crow M.K., Friedman S.M., T helper cell-dependent, microbial superantigen-induced murine B cell activiation: polyclonal and antigen-specific antibody responses, J. Immunol. 147 (1991) 432-238

[65] van Alstine W.G., Stevenson G.W., Kanitz C.L., Porcine reproductive and respiratory syndrome virus does not exacerbate Mycoplasma hyopneumoniae infection in young pigs, Vet. Microbiol. 49 (1995) 297-303.

[66] van Reeth K., Koyen A, Pensaert M., Clinical effects of dual infections with porcine epidemic abortion and respiratory syndrome virus, porcine respiratory coronavirus and swine influenza virus, Proceedings of the 13th International Pig Veterinary Congress, Bangkok, Thailand, 26th-30th June (1994) 51

[67] Vézina S.A., Loemba H., Fournier M., Dea S., Archambault D., Antibody-production and blastogenic response in pigs experimentally infected with porcine reproductive and respiratory syndrome virus, Can. J. Vet. Res. 60 (1996) 94-99.

[68] Voicu I.L., Interaction between PRRSV with swine monocytes, Vet. Rec. 134 (1994) 422-423.

[69] Wensvoort G., Terpstra C., Pol J.M.A., ter Laak E.A., Bloemraad M., de Kluyver E.P., Kragten C., van Buiten L., den Besten A., Wagenaar F., Broekhuijsen J.M., Moonen P.L.J.M., Zetstra T., de Boer E.A., Tibben H.J., de Jong M.F., van't Veld P., Groenland G.J.R., van Gennep J.A., Voets M.T., Verheijden J.H.M., Braamskamp J., Mystery swine disease in the Netherlands: the isolation of Lelystad virus, Vet. Q. 13 (1991) 121130.

[70] Wesley R.D., Mengeling W.L., Lager K.M., Prior infection of nursery-age pigs with porcine reproductive and respiratory syndrome virus does not affect the outcome of transmissible gastroenteritis virus challenge, J. Vet. Diagn. Invest. 10 (1998) 221-228.

[71] Yoon K.J., Zimmerman J.J., Swenson S.L., Wills R.W., Hill H.T., Platt K.B., Assessment of biological significance of antibody dependent enhancement (ADE) of porcine epidemic abortion and respiratory syndrome (PEARS) virus infection in passively immunised pigs, Proceedings of the 13th International Pig Veterinary Congress, Bangkok, Thailand, 26th-30th June (1994) 69 
[72] Zeman D.H., Concurrent Respiratory-Infections in 221 Cases of Prrs Virus Pneumonia - 19921994, Swine Health and Production 4 (1996) 143145.

[73] Zeman D., Neiger R., Yaeger M., Nelson E., Benfield D., Lesliesteen P., Thomson J., Miskimins D., Daly R., Minehart M., Laboratory investigation of PRRS virus infection in three swine herds, J. Vet. Diagn. Invest. 5 (1993) 522-528.
[74] Zhou Y., Barghusen S., Choi C., Rossow K., Collins J., Laber J., Molitor T., Murtaugh M., Effect of SIRS virus infection in leukocyte populations in the peripheral blood and on cytokine expression in alveolar macrophages of growing pigs, American Association of Swine Practitioners Newsletter 4 (1992) 28. 